\title{
Heuristic Based on Dynamic Weighting to Support Diagnosis with Two Minimization Focus in Alignment Incoherence Repair
}

\author{
Inne Gartina Husein, Benhard Sitohang, Saiful Akbar, and Fazat Nur Azizah \\ School of Electrical Engineering and Informatics, Institut Teknologi Bandung \\ Bandung, Indonesia \\ inne@tass.telkomuniversity.ac.id
}

\begin{abstract}
Ontology alignment is a collection of correspondences or mappings between entities from two ontologies being matched. Alignment is an essential data resource that used as a reference to build interlinking on Linked Data. Since it is produced by an ontology matching system, the good quality of alignment determines the good performance of the ontology matching system. The coherence of alignment is one of the success criteria of the ontology matching system so that some systems implement the alignment repair feature in it. This feature restores the incoherent to coherent by removing some mappings in alignment. Research of alignment incoherence stated that the repair process should have a minimum impact on alignment by minimizing the number of removed mappings and/or minimizing the confidence value of removed mappings. The study discussed in this paper is alignment repair to restore coherent conditions with two minimization focus of diagnosis. In a repair system, the process of finding and removing a mapping to produce conflict-free alignment is called the diagnosis. We have been proven that conflict-free alignment is coherent alignment. The proposed repair system implements a dynamic weighting heuristic to guide the search for minimum removed mapping with two minimization focus, in order to produce conflict-free alignment. Experiment on 8 alignments shows that the current system which removes more mapping will produce conflictfree alignment, but does not support minimal impact. Conversely, the current system that removes minimal mapping does not support conflict-free alignment. The proposed system excels at producing conflict-free alignment with minimal impact.
\end{abstract}

Keywords: Alignment, Removed Mapping, Incoherence, Minimal Impact, Conflict-free

\section{Introduction}

Ontology alignment is a collection of correspondences or mappings between entities from two ontologies being matched. Semantic Web researchers and practitioners use mapping on the ontology alignment (or alignment) to build interlinking on Linked Data [1]. As an important knowledge resource, mapping is also used to validate and correct links on Linked Data (LD) [2]. An initiative called Ontology Alignment Evaluation Initiatives (OAEI) periodically measures the quality of the alignment resulting from the ontology matching process. This initiative began to measure the degree of incoherence in 2008 [3]. The coherence of alignment is one of the success criteria of the ontology matching system, as well as a good determinant of the quality of the alignment itself [4]-[6]. Some ontology matching systems add alignment repair feature to restore the incoherent to coherent by removing some of the mappings in alignment.

However, there was a phenomenon of mapping removal up to $50 \%$ of each subalignment so that the alignment repair causes a large loss of knowledge resources [7]. Challenges arise when the alignment incoherence repair process must consider the smallest possible impact, such as the number of mappings removed or deleted must be as little as possible [8]-[10]. Since each mapping has a confidence value, which is a value that indicates the level of validity between entities, the deletion of the mapping must consider a smaller confidence value. This is intended so that the improvement process can maintain a mapping with high validity at the output alignment [11], [12]. Thus there are two minimal impacts in alignment repair, namely removing the mapping by considering (1) the smallest confidence value in the subalignment and (2) the

Received: March $27^{\text {th }}, 2019$. Accepted: February $25^{\text {th }}, 2020$ DOI: 10.15676/ijeei.2020.12.1.4 
least amount of elimination. In this paper, the term unwanted mapping is used for mapping that is (to be) removed from the alignment. A comparison of two minimal impacts on the improvement of alignment incoherence can be seen in Table 1 . The proposed system concerns a minimum focus 1 and 2 at once, so it is called two minimization focus repair or diagnosis [13]. Based on the considerations explained above, this study aims to improve alignment incoherence so that (1) it can restore coherent conditions and (2) have a minimum impact on alignment, with two minimization focus.

Table 1. Minimization Focus Comparison

\begin{tabular}{|c|c|c|c|c|}
\hline No & $\begin{array}{c}\text { Minimization } \\
\text { Focus }\end{array}$ & Advantages & Weaknesses & $\begin{array}{c}\text { Impact to Input } \\
\text { Alignment }\end{array}$ \\
\hline 1 & $\begin{array}{l}\text { Minimize the } \\
\text { confidence value of } \\
\text { unwanted mapping }\end{array}$ & $\begin{array}{l}\text { Avoid removing } \\
\text { mapping with high } \\
\text { validity }\end{array}$ & $\begin{array}{l}\text { The number of } \\
\text { removed mappings } \\
\text { greater than no. } 2\end{array}$ & $\begin{array}{l}\text { Major changes, when } \\
\text { removing much more } \\
\text { mapping }\end{array}$ \\
\hline 2 & $\begin{array}{l}\text { Minimize the } \\
\text { number of unwanted } \\
\text { mapping }\end{array}$ & $\begin{array}{l}\text { Avoid removing } \\
\text { large number of } \\
\text { mapping }\end{array}$ & $\begin{array}{l}\text { Ignoring the high } \\
\text { validity of mapping } \\
\text { when repairing }\end{array}$ & $\begin{array}{l}\text { Major changes, when } \\
\text { most of unwanted } \\
\text { mapping have high } \\
\text { confidence value }\end{array}$ \\
\hline
\end{tabular}

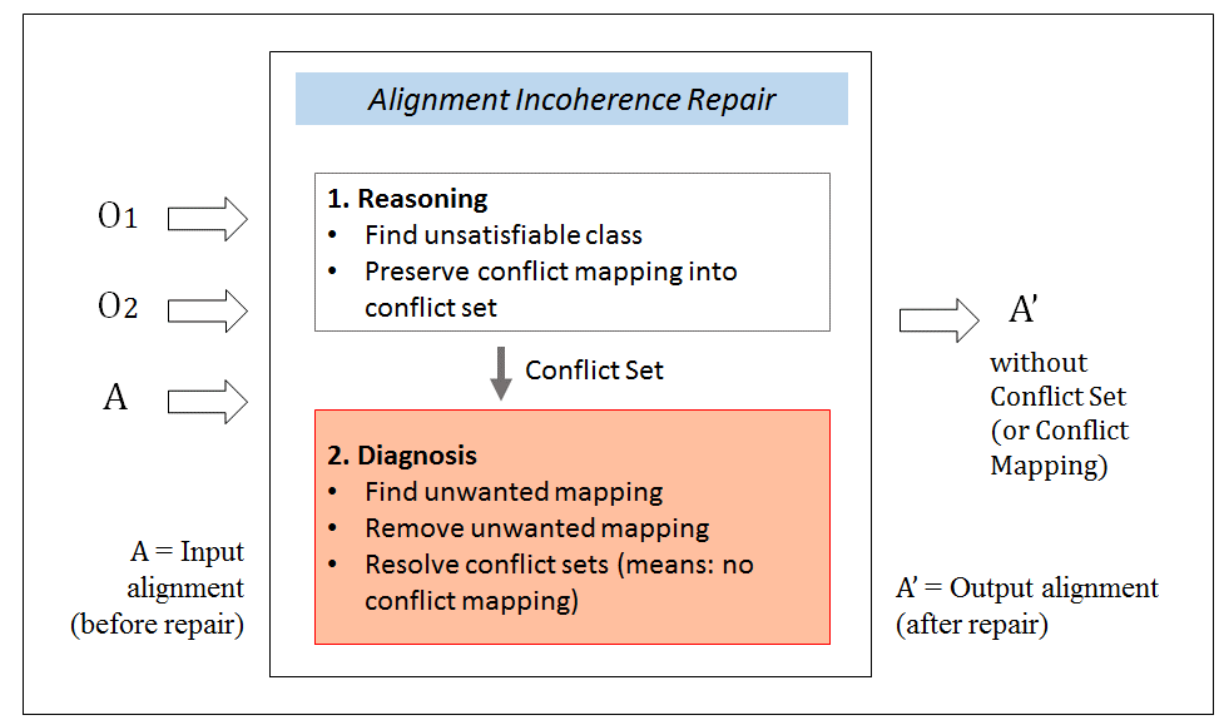

Figure 1. Alignment Incoherence Repair Subprocesses

Alignment incoherence repair process (or repair) can be divided into two main subprocesses namely reasoning and diagnosis (Figure 1). Subprocess reasoning that is looking for unsatisfiable class and preserves conflict mappings into conflict sets. Subprocess diagnosis is finding and removing unwanted mapping, and resolving conflict sets [14]. The repair process produces an output alignment that is free of conflict mapping where the main characteristic of the absence of unsatisfiable is the absence of conflict mapping so that the alignment is declared coherent. In order to support this statement, in section 6 we check the absence of unsatisfiable concepts in alignment that are free from conflict mapping. Diagnosis with two minimization focus to produce conflict-free mapping (or alignment) is the main discussion of this study.

The proposed repair system implements a Greedy search method with a dynamic weighting heuristic to find unwanted mapping with two minimization focus in order to repair alignment incoherence with minimal impact. Since Alcomo carries out a diagnosis with two minimization 
focus as well (Table 3), then the testing in this study will be compared with the two repair systems from Alcomo [15], [16]. The test also compares with an A* Search method repair system that was developed in 2018 with the dynamic weighting technique and the median rule applied therein [17].

The presentation of this paper is arranged as follows. Section 2 provides work related to the existing repair system. Section 3 explains the formal definition of some terms used in this paper. Section 4 provides a brief of the search method, mapping and conflict mapping from an alignment of the Conference and Ekaw ontologies. Section 5 explains the dynamic weighting heuristic. Section 6 provides the experiments result using eight alignments. Section 7 concludes the study in this paper.

\section{Related Work}

Ontology alignment results from the ontology matching process by the matching system. A literature study has been carried out on the performance of the matching system from the OAEI page and it was found that the matching system that has alignment incoherence repair feature in it, produces a higher quality alignment [18]. There are three matching systems that have a repair feature and are ranked in the top three namely LogMap, Agreement MakerLight and Xmap (Table 2). Repair features implemented by these systems are LogMap Repair, AML Repair and Alcomo [19].

Table 2. Matching System Comparison

\begin{tabular}{|r|r|c|c|c|c|c|c|}
\hline \multicolumn{2}{|r|}{ System Name } & BLOOMS & WikiMatch & YAM++ & $\begin{array}{c}\text { Agreement } \\
\text { MakerLight }\end{array}$ & LogMap & Xmap \\
\hline \multicolumn{2}{|r|}{ Feature } & $\begin{array}{c}\text { Matching } \\
\text { System }\end{array}$ & $\begin{array}{c}\text { Matching } \\
\text { System }\end{array}$ & $\begin{array}{c}\text { Matching } \\
\text { System }\end{array}$ & $\begin{array}{c}\text { Matching } \\
\text { System } \\
+ \text { AML } \\
\text { Repair }\end{array}$ & $\begin{array}{c}\text { Matching } \\
\text { System } \\
+ \text { LogMap } \\
\text { Repair }\end{array}$ & $\begin{array}{c}\text { Matching } \\
\text { System } \\
+ \text { Alcomo }\end{array}$ \\
\hline $\begin{array}{c}\text { OAEI } \\
\text { Participant }\end{array}$ & $\begin{array}{r}\text { Evaluation } \\
\text { Result }\end{array}$ & Best Sixth & Middle & Best First & Best Three & Best Three & Best Three \\
\cline { 2 - 8 }
\end{tabular}

Table 3. Current Alignment Incoherence Repair System

\begin{tabular}{|c|l|l|}
\hline No & \multicolumn{1}{|c|}{ System (Year) } & \multicolumn{1}{|c|}{ Minimization Focus } \\
\hline 1 & LogMap-R (2011) & $\begin{array}{l}\text { Focus 1 : Minimize the confidence value of unwanted } \\
\text { mapping }\end{array}$ \\
\hline 2 & AMLR (2014) & Focus 2 : Minimize the number of unwanted mapping \\
\hline 3 & Alcomo (2011) & Focus 1 and 2 \\
\hline
\end{tabular}

The three repair features have a different minimization focus (Table 3). LogMap Repair (LogMap-R) focuses on minimizing confidence values (focus 1), AML Repair (AMLR) focuses on minimizing the number of unwanted mapping (focus 2), while Alcomo focuses on two minimizations [10], [12]. A diagnosis that emphasizes focus 1 will ignore the number of unwanted mappings so that the system removes more mapping in alignment [13], [20]. A diagnosis that emphasizes focus 2 will ignore the confidence value. Mapping with a larger confidence value is a mapping with a higher level of validity, which means having a higher knowledge resource [21], [22]. A diagnosis that emphasizes on two minimization focus remove minimal mapping and remain higher validity mapping (Table 1). This study concern with producing output alignment without conflict mapping. Alcomo left conflict mapping in some of the output alignments so that the ones remain incoherent (section 6). The system proposed in this 
Inne Gartina Husein et al.

study emphasizes two minimization focus to produce conflict-free mapping so that coherent alignment is obtained.

\section{Foundation}

OAEI states that the recent work of ontology matching leads to thousands of unsatisfiable concepts [7], [11], [23]. A set of mappings that leads to an unsatisfiable concept is referred to as incoherence [24]. For concept or class C, C is unsatisfiable when C is subsumed by $\perp$ [25].

Definition 1: Mapping. Mappings are conceptualized as 4-tuples of the form $\left(\mathrm{e}_{1}, \mathrm{e}_{2}, \mathrm{n}, \rho\right)$, with $\mathrm{e}_{1}, \mathrm{e}_{2}$ are entities of input ontologies $\mathrm{O} 1$ and $\mathrm{O}_{2}, \mathbf{n}$ is confidence value between 0 and 1 , and $\rho$ is a relation between $\mathrm{e}_{1}$ and $\mathrm{e}_{2}$.

The confidence value $\mathbf{n}$ describes the trust in the correctness of a mapping [26]. A large $\mathbf{n}$ or close to 1 explains that the two entities are increasingly matched (or similar) or can also be said to be high validity, and vice versa for a small $\mathbf{n}$ or close to 0 . The confidence value managed during the ontology matching process, using the technique to determine the similarity between entities or concepts from different ontologies [27].

Definition 2: Mapping Incoherence. A set of mappings $\mathrm{M}$ is incoherent with respect to $\mathrm{O}_{1}$ and $\mathrm{O}_{2}$ if there exists a class $\mathrm{C}$ in signature $\left(\mathrm{O}_{1} \cup \mathrm{O}_{2}\right)$ such that $\mathrm{O} 1 \mathrm{UO} 2 \not \neq \mathrm{C} \subseteq \perp$ and $\mathrm{O} 1 \mathrm{UO} 2 \mathrm{UM}$ $\vDash \mathrm{C} \subseteq \perp$.

In the above formal definition, $\subseteq$ denotes the subsumption relation, $\vDash$ denotes the semantic consequences ( where $\not$ is the opposite of $\vDash$ ) and signature $(\mathrm{O})$ denotes the set of classes in the signature of ontology $\mathrm{O}$ [24]. The empty set (symbolized $\perp$ ) in definition 2 is known as an unsatisfiable concept or class in Description Logic terms [25].

Definition 3: Alignment Incoherence. Alignment $\mathrm{A}$ is incoherent with respect to $\mathrm{O} 1$ and $\mathrm{O}_{2}$ if there exists mapping incoherence $\mathrm{M} \subseteq \mathrm{A}$ with respect to $\mathrm{O}_{1}$ and $\mathrm{O}_{2}$.

Based on definition 3, if all mappings in an alignment are coherent then the alignment is declared coherent. Conversely, if there are one or more incoherent mappings in alignment, the alignment is declared incoherent.

Definition 4: Alignment Repair. Let $\mathrm{M}$ be an incoherent set of mappings with respect to $\mathrm{O} 1 \mathrm{UO} 2$. A set of mappings $\mathcal{U} \subseteq \mathrm{M}$ is an alignment repair for $\mathrm{M}$ with respect to $\mathrm{O}_{1}$ and $\mathrm{O}_{2}$ if $\mathrm{M} \backslash \mathcal{U}$ is coherent with respect to $\mathrm{O} 1$ and $\mathrm{O} 2$.

Alignment repair returns the coherence condition by removing part of the mapping. Removed mappings are called unwanted mapping and symbolized $\mathcal{U}$. It is known that the unsatisfiable concept causes conflicts between mapping in alignment, removing unwanted mapping eliminates conflict mapping and makes a set of mappings (and alignments) coherent [6], [11], [27], [28].

Definition 5: Conflict Mapping (CM). CM is a minimal incoherence of $\mathrm{M}$ that preserves in Conflict Set (CS), and there exists no $\mathrm{CM} \backslash \mathcal{U}$ that is incoherent with respect to $O 1$ and $O 2$.

When the unsatisfiable concept is found, the repair system preserves CM into a conflict set (CS), where each CS contains two CM. In the process of choosing unwanted mapping (Figure 5), it is stated that each $\mathrm{CM} \backslash \mathcal{U}$ process will resolve or release CS.

\section{Informed Search Method, Mapping and Conflict Set in Alignment Conference - Ekaw \\ A. Informed Search Method}

The informed search method is a method of evaluating search space based on heuristic functions $(h(n))$. The informed search method includes Best-first, A *, and Greedy search [29]. Best-first search evaluate a node by function $f(n)=g(n)+h(n)$. Estimated cost (symbolized by $g(n))$ is a value measurable from search space, and the heuristic function (symbolized by $h(n)$ ) as an educated guess [30]. Good heuristics can produce the closest path because it has shorter steps [31]. Greedy Best-first evaluates nodes by using an only heuristic function, that is $f(n)=$ $h(n)$, made this method to lead to a solution quickly. A* search is a variant of Best-first with a more complex way of calculating $h(n)$, where the value of $h(n)$ must be optimal. Two conditions 
that affect optimality in heuristic are admissibility and consistency. An admissible heuristic is one that never overestimates the cost to reach the goal [29]. Consistent is also called monotonic, which means that the heuristic value will always decrease until reaching the goal [21].

The proposed system uses the Greedy Best-first (or Greedy) search method, which heuristic function guide the selection of $U$ in the search area. The experiment result of this system is compared to current systems that carry out a minimal diagnosis using $A^{*}$ and Greedy search methods (in section 6).

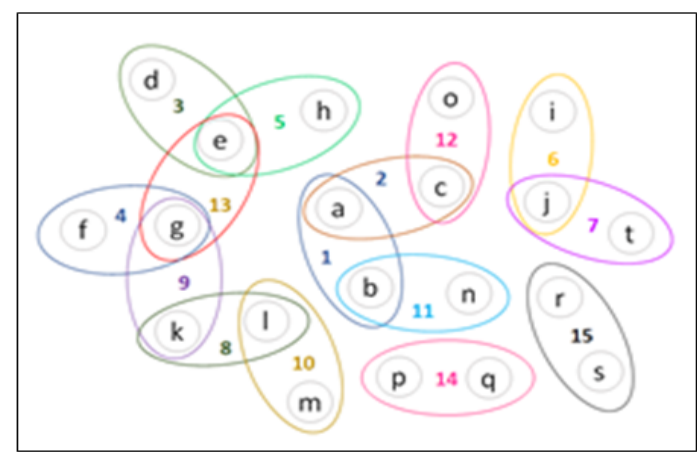

Figure 2. Intersect in Conflict Sets

B. Conflict Mapping and Conflict Set in Alignment Conference - Ekaw

Table 4. Conflict Set Conference - Ekaw Alignment

\begin{tabular}{|c|c|c|c|}
\hline $\begin{array}{l}\mathrm{ID}_{-} \\
\mathrm{CS}\end{array}$ & $\begin{array}{l}\text { ID_- } \\
\text { Mapp }\end{array}$ & Mapping & $\begin{array}{l}\text { Confidence } \\
\text { Value }(\mathrm{CV})\end{array}$ \\
\hline \multirow{2}{*}{1} & $\mathrm{a}$ & O1\#Person $=02 \#$ Person & 0.733825 \\
\hline & $\mathrm{b}$ & O1\#Conference_applicant $=$ O2\#Conference_Session & 0.428498 \\
\hline \multirow{2}{*}{2} & $\mathrm{a}$ & $\mathrm{O} 1 \#$ Person $=\mathrm{O} 2 \#$ Person & 0.733825 \\
\hline & $\mathrm{c}$ & O1\#Regular_author $=$ O2\#Regular_Session & 0.351035 \\
\hline \multirow{2}{*}{3} & $\mathrm{~d}$ & O1\#Invited_talk $=$ O2\#Invited_Talk & 0.698590 \\
\hline & $\mathrm{e}$ & $\mathrm{O} 1 \#$ Conference_contribution $=\mathrm{O} 2 \#$ Conference_Trip & 0.384258 \\
\hline \multirow{2}{*}{4} & f & O1\#Conference_document $=\mathrm{O} 2 \#$ Document & 0.563702 \\
\hline & $\mathrm{g}$ & O1\#has_a_review $=02 \#$ reviewerOfPaper & 0.314466 \\
\hline \multirow{2}{*}{5} & $\mathrm{~h}$ & O1\#Presentation $=02 \#$ Individual_Presentation & 0.561154 \\
\hline & $\mathrm{e}$ & O1\#Conference_contribution = $\mathrm{O} 2 \#$ Conference_Trip & 0.384258 \\
\hline \multirow{2}{*}{6} & $\mathrm{i}$ & O1\#Poster = O2\#Poster_Paper & 0.552193 \\
\hline & $\mathrm{j}$ & $\mathrm{O} 1 \#$ Paper $=\mathrm{O} 2 \#$ Paper & 0.531727 \\
\hline \multirow{2}{*}{7} & $\mathrm{j}$ & $\mathrm{O} 1 \#$ Paper $=\mathrm{O} 2 \# \mathrm{P}$ aper & 0.531727 \\
\hline & $\mathrm{t}$ & O1\#Regular_contribution = O2\#Regular_Paper & 0.398834 \\
\hline \multirow{2}{*}{8} & $\mathrm{k}$ & O1\#Submitted_contribution = O2\#Submitted_Paper & 0.450786 \\
\hline & 1 & O1\#Camera_ready_contribution $=$ O2\#Camera_Ready_Paper & 0.433526 \\
\hline \multirow{2}{*}{9} & $\mathrm{k}$ & O1\#Submitted_contribution $=$ O2\#Submitted_Paper & 0.450786 \\
\hline & $\mathrm{g}$ & O1\#has_a_review $=$ O2\#reviewerOfPaper & 0.314466 \\
\hline \multirow{2}{*}{10} & 1 & O1\#Camera_ready_contribution $=\mathrm{O} 2 \#$ Camera_Ready_Paper & 0.433526 \\
\hline & $\mathrm{m}$ & O1\#Accepted_contribution = O2\#Accepted_Paper & 0.417688 \\
\hline \multirow{2}{*}{11} & $\mathrm{~b}$ & O1\#Conference_applicant $=\mathrm{O} 2 \#$ Conference_Session & 0.428498 \\
\hline & $\mathrm{n}$ & O1\#Registeered_applicant $=\mathrm{O} 2 \#$ Presenter & 0.360214 \\
\hline \multirow{2}{*}{12} & o & O1\#Conference_contributor $=\mathrm{O} 2 \# \mathrm{Paper}$ A Author & 0.390751 \\
\hline & $\mathrm{c}$ & O1\#Regular_author = O2\#Regular_Session & 0.351035 \\
\hline \multirow{2}{*}{13} & $\mathrm{e}$ & O1\#Conference_contribution = O2\#Conference_Trip & 0.384258 \\
\hline & $\mathrm{g}$ & O1\#has_a_review $=02 \#$ reviewerOfPaper & 0.314466 \\
\hline \multirow{2}{*}{14} & $\mathrm{p}$ & O1\#Organizing_committee $=\mathrm{O} 2 \#$ Organising_Agency & 0.380003 \\
\hline & $\mathrm{q}$ & O1\#was_an_organizing_committee_of $=\mathrm{O} 2 \#$ scientificallyOrganises & 0.332029 \\
\hline \multirow{2}{*}{15} & $\mathrm{r}$ & O1\#Conference_volume $=\mathrm{O} 2 \#$ Multi-author_Volume & 0.354819 \\
\hline & s & O1\#has_a_steering_committee $=02 \#$ reviewWrittenBy & 0.337878 \\
\hline
\end{tabular}


Ontology is a collection of vocabularies arranged hierarchically [32]. A collection of ontology with a Conference domain developed by a project called Ontofarm Project and has been used by various ontology matching systems [33], [34]. An example of a mapping in the alignment of the Ontology Conference $(\mathrm{O} 1)$ and Ekaw $\left(\mathrm{O}_{2}\right)$ is below. This alignment is produced by a matching system called CSA.

\section{(O1\#Conference_applicant, O2\#Conference_Session, 0.428498,=)}

$\mathrm{O} 1$ and $\mathrm{O}_{2}$ are two ontologies being matched after the fence sign (\#) are followed by the name of the entity in each ontology. The equal sign $(=)$ indicates the type of similar equivalence relationship between the two entities. The decimal number indicates the confidence value of the relationship. Each mapping has a confidence value between 0 and 1 . There are 20 mappings in that alignment, each of which has been assigned a to t (see Table 4). After coherency checking, conflict mappings (CM) are grouped into conflict sets (CS) as seen in Figure 2. The ellipse represents CS.

Figure 2 illustrates the intersect mapping in the conflict sets, where some mappings appear in more than one CS. For example, mapping $\mathbf{e}$ is an intersect mapping because it appears in CS ID 3, 5, and 13. Each CS contains two CM as seen in Table 4. If one CM is removed, the system will release or resolve CSs containing the CM and the CM pair -that is on the same CS- is no longer CM (see definition 5: Conflict Mapping). If all CS is resolved, it means that there is no more CM in the alignment. Resolving all CS in alignment is the purpose of the study presented in this paper.

\section{Heuristic Based on Dynamic Weighting}

Weighting is giving a specific value to each node that is being evaluated, where these weights will be changing according to the updated CS releasement, this is called dynamic weighting. Before doing weighting for mapping, the system must determine the weights for a certain intersect number [35].

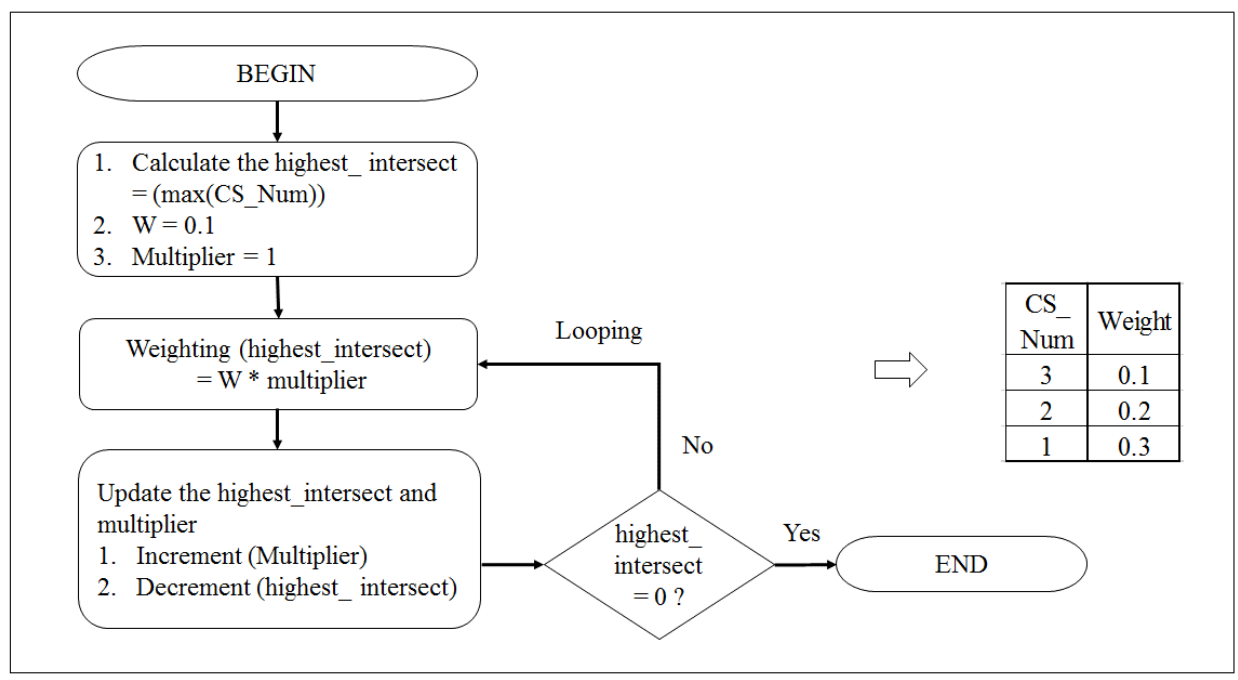

Figure 3. The logic of Determining Weights

First, the system calculates the highest intersect number (max (CS_Num)), which is owned by all $\mathrm{CM}$ in alignment. The highest intersect number is weight 0.1 (lowest weight), then the system repeats the weighting for the next number of intersects, repetition is done until the lowest intersect number. The logic of determining weights can be seen in Figure 3. The lowest weight of 0.1 is given to the mapping with the highest number of intersects, this is because the greedy 
search method will first evaluate the node that has the lowest $h$ (node). Since the Greedy method evaluates nodes based only on $h$ (node), any positive number can be used as weights. We use a decimal number as weights to adjust to the confidence value which is also a decimal.

Table 5. Weight h on Mapping

\begin{tabular}{|c|c|c|c|}
\hline $\begin{array}{c}\text { ID_ } \\
\text { Mapp }\end{array}$ & $\begin{array}{c}\text { CS_ } \\
\text { Num }\end{array}$ & CS_List & $\begin{array}{c}\text { Weight } \\
\text { h }\end{array}$ \\
\hline $\mathrm{a}$ & 2 & 1,2 & 0.2 \\
\hline $\mathrm{b}$ & 2 & 1,11 & 0.2 \\
\hline $\mathrm{c}$ & 2 & 2,12 & 0.2 \\
\hline $\mathrm{d}$ & 1 & 3 & 0.3 \\
\hline $\mathrm{e}$ & 3 & $3,5,13$ & 0.1 \\
\hline $\mathrm{f}$ & 1 & 4 & 0.3 \\
\hline $\mathrm{g}$ & 3 & $4,9,13$ & 0.1 \\
\hline $\mathrm{h}$ & 1 & 5 & 0.3 \\
\hline $\mathrm{i}$ & 1 & 6 & 0.3 \\
\hline $\mathrm{j}$ & 2 & 6,7 & 0.2 \\
\hline $\mathrm{k}$ & 2 & 8,9 & 0.2 \\
\hline $\mathrm{l}$ & 2 & 8,10 & 0.2 \\
\hline $\mathrm{m}$ & 1 & 10 & 0.3 \\
\hline $\mathrm{n}$ & 1 & 11 & 0.3 \\
\hline $\mathrm{o}$ & 1 & 12 & 0.3 \\
\hline $\mathrm{p}$ & 1 & 14 & 0.3 \\
\hline $\mathrm{q}$ & 1 & 14 & 0.3 \\
\hline $\mathrm{r}$ & 1 & 15 & 0.3 \\
\hline $\mathrm{s}$ & 1 & 15 & 0.3 \\
\hline $\mathrm{t}$ & 1 & 7 & 0.3 \\
\hline & & & \\
\hline
\end{tabular}

Table 6. Updating Weight h on Mapping

\begin{tabular}{|c|c|c|c|c|c|}
\hline $\begin{array}{c}\text { ID_ } \\
\text { Mapp }\end{array}$ & $\begin{array}{c}\text { CS_ } \\
\text { Num }\end{array}$ & CS_List & $\begin{array}{c}\text { h(mapp } \\
\text { ing) }\end{array}$ & $\begin{array}{c}\text { CS_Num } \\
\text { update }\end{array}$ & h updated \\
\hline a & 2 & 1,2 & 0.2 & & 0.2 \\
\hline b & 2 & 1,11 & 0.2 & & 0.2 \\
\hline c & 2 & 2,12 & 0.2 & & 0.2 \\
\hline d & 1 & 3 & 0.3 & & 0.3 \\
\hline e & 3 & $3,5,13$ & 0.1 & $3->2$ & 0.2 \\
\hline f & 1 & 4 & 0.3 & 1 -> 0 & \\
\hline g & 3 & $4,9,13$ & \multicolumn{1}{|c|}{ removed in LOOP 1} \\
\hline h & 1 & 5 & 0.3 & & 0.3 \\
\hline i & 1 & 6 & 0.3 & & 0.3 \\
\hline j & 2 & 6,7 & 0.2 & & 0.2 \\
\hline k & 2 & 8,9 & 0.2 & $2->1$ & 0.3 \\
\hline 1 & 2 & 8,10 & 0.2 & & 0.2 \\
\hline m & 1 & 10 & 0.3 & & 0.3 \\
\hline n & 1 & 11 & 0.3 & & 0.3 \\
\hline o & 1 & 12 & 0.3 & & 0.3 \\
\hline p & 1 & 14 & 0.3 & & 0.3 \\
\hline q & 1 & 14 & 0.3 & & 0.3 \\
\hline r & 1 & 15 & 0.3 & & 0.3 \\
\hline s & 1 & 15 & 0.3 & & 0.3 \\
\hline t & 1 & 7 & 0.3 & & 0.3 \\
\hline
\end{tabular}

The weight $\mathrm{h}$ is given to mapping based on the number of intersects, shown in the CS_Num column (see Table 5). A mapping that has the largest CS_Num will be given the smallest weight and will be the priority node to be evaluated first. If a mapping that has as many as 3 CS intersects is removed from an alignment, then the deletion will resolve $3 \mathrm{CS}$ at a time. This is done to 
minimize the number of removed mapping (or $\mathcal{U}$ ) in the repair process. A mapping which has the smallest CS_Num (i.e., 1) will be given the highest weight, and not be the priority node to be evaluated unless there is no more mapping with a bigger CS_Num than that. This is done to avoid eliminating more mapping in the repair process.

The average weight for each CS is based on the average weights of CMs in each CS. If there are several average weights $h$ in one loop, the system will choose the smallest value to evaluate (see Table 7). If there is a change in the weight $h$ of a mapping, it will cause a change in the average weight $h$ on CS. This is called dynamic weighting, which applies to both weights $h$ and average $\mathrm{h}$ (see Figure 4). If the unwanted mapping has been determined and mapping has been removed in one loop, the number in CS_Num will change according to the number of intersecting updates (see Table 6). Mapping $\mathbf{g}$ is removed in the first loop, causing changes to the weight $\mathrm{h}$ of mapping $\mathbf{e}, \mathbf{f}$, and $\mathbf{k}$. Thus, the weight $\mathrm{h}$ will change continuously according to the number of intersecting updated, as illustrated in Figure 4.

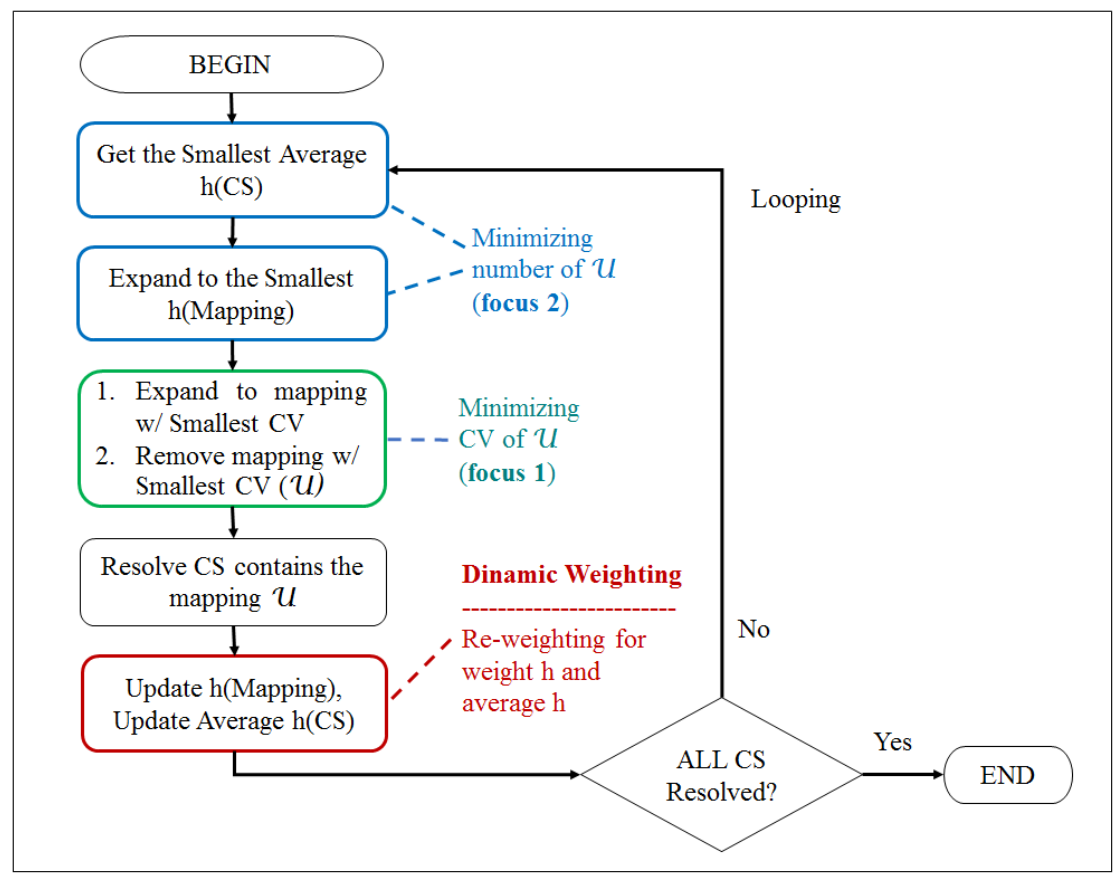

Figure 4. The logic of Choosing Unwanted Mapping with Dynamic Weighting

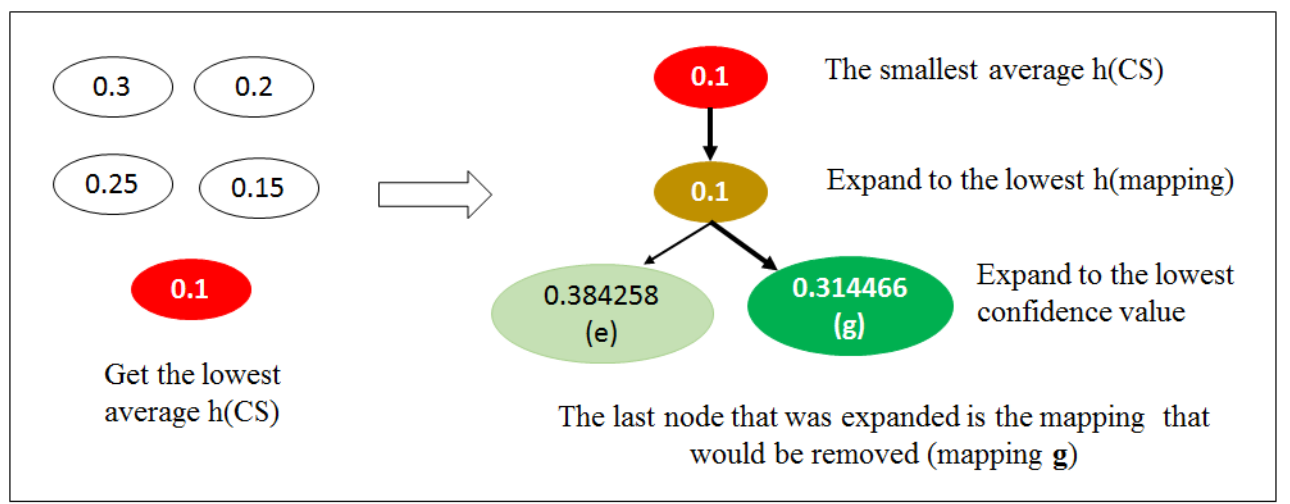

Figure 5. Expanding Nodes 
Table 7. Average weight $\mathrm{h}$ on $\mathrm{CS}$

\begin{tabular}{|c|c|c|c|c|}
\hline ID_CS & $\mathrm{CV}$ & $\begin{array}{l}\text { ID_ } \\
\text { Mapp }\end{array}$ & $\mathrm{h}$ (mapping) & $\begin{array}{c}\text { Average } \\
\text { h(CS) }\end{array}$ \\
\hline \multirow{2}{*}{1} & 0.733825 & $\mathrm{a}$ & 0.2 & \multirow{2}{*}{0.2} \\
\hline & 0.428498 & $\mathrm{~b}$ & 0.2 & \\
\hline \multirow{2}{*}{2} & 0.733825 & $\mathrm{a}$ & 0.2 & \multirow{2}{*}{0.2} \\
\hline & 0.351035 & c & 0.2 & \\
\hline \multirow{2}{*}{3} & 0.698590 & d & 0.3 & \multirow{2}{*}{0.2} \\
\hline & 0.384258 & $\mathrm{e}$ & 0.1 & \\
\hline \multirow{2}{*}{4} & 0.563702 & $f$ & 0.3 & \multirow{2}{*}{0.2} \\
\hline & 0.314466 & $\mathrm{~g}$ & 0.1 & \\
\hline \multirow{2}{*}{5} & 0.561154 & $\mathrm{~h}$ & 0.3 & \multirow{2}{*}{0.2} \\
\hline & 0.384258 & $\mathrm{e}$ & 0.1 & \\
\hline \multirow{2}{*}{6} & 0.552193 & $\mathrm{i}$ & 0.3 & \multirow{2}{*}{0.25} \\
\hline & 0.531727 & j & 0.2 & \\
\hline \multirow{2}{*}{7} & 0.531727 & $\mathrm{j}$ & 0.2 & \multirow{2}{*}{0.25} \\
\hline & 0.398834 & $t$ & 0.3 & \\
\hline \multirow{2}{*}{8} & 0.450786 & $\mathrm{k}$ & 0.2 & \multirow{2}{*}{0.2} \\
\hline & 0.433526 & 1 & 0.2 & \\
\hline \multirow{2}{*}{9} & 0.450786 & $\mathrm{k}$ & 0.2 & \multirow{2}{*}{0.15} \\
\hline & 0.314466 & $\mathrm{~g}$ & 0.1 & \\
\hline \multirow{2}{*}{10} & 0.433526 & 1 & 0.2 & \multirow{2}{*}{0.25} \\
\hline & 0.417688 & $\mathrm{~m}$ & 0.3 & \\
\hline \multirow{2}{*}{11} & 0.428498 & $\mathrm{~b}$ & 0.2 & \multirow{2}{*}{0.25} \\
\hline & 0.360214 & $\mathrm{n}$ & 0.3 & \\
\hline \multirow{2}{*}{12} & 0.390751 & o & 0.3 & \multirow{2}{*}{0.25} \\
\hline & 0.351035 & $\mathrm{c}$ & 0.2 & \\
\hline \multirow{2}{*}{13} & 0.384258 & $\mathrm{e}$ & 0.1 & \multirow{2}{*}{0.1} \\
\hline & 0.314466 & $\mathrm{~g}$ & 0.1 & \\
\hline \multirow{2}{*}{14} & 0.380003 & $\mathrm{p}$ & 0.3 & \multirow{2}{*}{0.3} \\
\hline & 0.332029 & $q$ & 0.3 & \\
\hline \multirow{2}{*}{15} & 0.354819 & $\mathrm{r}$ & 0.3 & \multirow{2}{*}{0.3} \\
\hline & 0.337878 & $\mathrm{~s}$ & 0.3 & \\
\hline
\end{tabular}

Parent nodes, namely average h (CS), which has the smallest value will be evaluated first. The average $h(C S)$ indicates a CS that has two mappings with the smallest weight $h$. The smallest weight $h$ means mapping with the highest number of intersects (in the CS_Num column). The system prioritizes the lowest average $\mathrm{h}$ (CS) to be evaluated, this will search as little as possible the unwanted mapping. When $\mathcal{U}$ is found and removed then the system resolves CS(s) at once.

After the lowest average $h$ (CS) node is selected, the system expands (and evaluates) the node with the smallest $h$ (mapping) weight. Once a node with the smallest $h$ weight is found, then the system chooses a node with the smallest confidence value and removes it (called $\mathcal{U}$ ). Illustration of this explanation can be seen in Figure 5 and Table 7. Dynamic weighting helps diagnosis with two minimization focus to restore incoherent to coherent alignment.

\section{Experiments and Results}

Experiments have been carried out using eight alignments from the Conference domain ontology (see Table 8). These alignments are produced by the Cluster-based Similarity Aggregation (CSA) system, which was developed in 2011 [34], [36]. Alignment 1 and 2 have a 0.3 threshold applied to the evaluated mapping set to narrow down the search area, as was done in the previous study [35]. The conflict sets in 8 alignments (Table 8) indicate the presence of conflict mapping because of the existence of unsatisfiable. The experiment aims to test the proposed system -which implements dynamic weighting- to produce a coherent alignment with two minimal impacts. The proposed repair system will stop to search for unwanted mapping once all CS has been resolved (Figure 4), meaning that there is no conflict mapping remain in output alignment. 
Inne Gartina Husein et al.

Table 8. Alignment List

\begin{tabular}{|c|l|c|c|}
\hline No & \multicolumn{1}{|c|}{$\begin{array}{c}\text { Alignment of } \\
\text { Ontology Pair }\end{array}$} & $\begin{array}{c}\text { Mapping } \\
\text { Number }\end{array}$ & $\begin{array}{c}\text { Conflict } \\
\text { Set }\end{array}$ \\
\hline 1 & CONFERENCE-EKAW & 66 & 15 \\
\hline 2 & CMT-EKAW & 28 & 15 \\
\hline 3 & CONFOF - SIGKDD & 46 & 20 \\
\hline 4 & EKAW - IASTED & 88 & 46 \\
\hline 5 & CMT - CONFERENCE & 54 & 28 \\
\hline 6 & EDAS - EKAW & 91 & 137 \\
\hline 7 & CONFERENCE - SIGKDD & 98 & 28 \\
\hline 8 & IASTED - SIGKDD & 121 & 19 \\
\hline
\end{tabular}

Table 9. Repair System List

\begin{tabular}{|c|c|c|c|}
\hline $\begin{array}{c}\text { Repair } \\
\text { System }\end{array}$ & $\begin{array}{c}\text { Informed } \\
\text { Search } \\
\text { Method }\end{array}$ & $\begin{array}{c}\text { Type } \\
\text { (Year) }\end{array}$ & $\begin{array}{c}\text { System/ } \\
\text { Developer }\end{array}$ \\
\hline A & $\begin{array}{c}\text { Greedy } \\
\text { Best-first }\end{array}$ & $\begin{array}{c}\text { Current } \\
(2012)\end{array}$ & Alcomo \\
\hline B & $\begin{array}{c}\text { Greedy } \\
\text { Best-first }\end{array}$ & $\begin{array}{c}\text { Proposed } \\
(2019)\end{array}$ & Husein \\
\hline C & A $^{*}$ & $\begin{array}{c}\text { Current } \\
(2012)\end{array}$ & Alcomo \\
\hline D & A $^{*}$ & $\begin{array}{c}\text { Developed } \\
(2018)\end{array}$ & Husein \\
\hline
\end{tabular}

Table 9 shows the list of repair systems tested. Four repair systems used in the experiment, two are current systems, one is developed in 2018 and one is the proposed system. The current system is a system that has been implemented by researchers before 2018. The search methods that have been implemented in these systems are Greedy Search (system A), A* Search (system $\mathrm{C}$ and D) [15], [35] and the proposed system (system B).

Table 10. Removing Result

\begin{tabular}{|c|c|c|c|c|c|c|c|c|c|c|c|c|c|c|c|c|}
\hline $\begin{array}{l}\text { llignment } \\
\text { No. }\end{array}$ & & & & & & & & \\
\hline $\begin{array}{l}\text { Repair } \\
\text { System }\end{array}$ & $\begin{array}{c}\text { Remo } \\
\text { ved } \\
\text { (i) }\end{array}$ & $\begin{array}{c}\text { Total } \\
\mathrm{CV} \\
\text { (ii) }\end{array}$ & $\begin{array}{c}\text { Remo } \\
\text { ved } \\
\text { (iii) }\end{array}$ & \begin{tabular}{|c|} 
Total \\
$\mathrm{CV}$ \\
(iv)
\end{tabular} & $\begin{array}{c}\text { Remo } \\
\text { ved } \\
\text { (v) }\end{array}$ & \begin{tabular}{|c} 
Total \\
$\mathrm{CV}$ \\
(vi)
\end{tabular} & $\begin{array}{c}\text { Remo } \\
\text { ved } \\
\text { (vii) }\end{array}$ & \begin{tabular}{|c} 
Total \\
$\mathrm{CV}$ \\
(viii)
\end{tabular} & $\begin{array}{c}\text { Remo } \\
\text { ved } \\
\text { (ix) }\end{array}$ & $\begin{array}{l}\text { Total } \\
\mathrm{CV} \\
\text { (x) }\end{array}$ & $\begin{array}{c}\text { Remo } \\
\text { ved } \\
\text { (xi) }\end{array}$ & $\begin{array}{c}\text { Total } \\
\mathrm{CV} \\
\text { (xii) }\end{array}$ & $\left|\begin{array}{c}\text { Remo } \\
\text { ved } \\
\text { (xiii) }\end{array}\right|$ & $\begin{array}{c}\text { Total } \\
\mathrm{CV} \\
\text { (xiv) }\end{array}$ & $\begin{array}{c}\text { Remo } \\
\text { ved } \\
(\mathrm{xv})\end{array}$ & \begin{tabular}{|c} 
Total \\
$\mathrm{CV}$ \\
(xvi)
\end{tabular} \\
\hline A & 8 & 3.11342 & 5 & 1.75046 & 10 & 2.70312 & 9 & 2.37522 & 14 & 4.8210 & 46 & 14.454 & 16 & 10.8712 & 17 & 12.381 \\
\hline B & 8 & 3.11342 & 6 & 2.7237 & 7 & 2.23964 & 9 & 2.37522 & 12 & 3.9244 & 26 & 9.1899 & 16 & 10.8713 & 14 & 10.418 \\
\hline C & 8 & 3.11342 & 5 & 1.75046 & 7 & 2.23964 & 9 & 2.37522 & 12 & 3.92427 & 26 & 9.1897 & 15 & 10.4052 & 14 & 10.418 \\
\hline D & 8 & 3.11342 & 5 & 1.75046 & 10 & 2.70312 & 9 & 2.37522 & 15 & 4.6115 & 20 & 5.0784 & 16 & 10.7555 & 12 & 8.2197 \\
\hline
\end{tabular}

Table 11. Repair Size Based on Number of Removed Mapping

\begin{tabular}{|c|c|c|c|c|c|c|c|c|c|}
\hline \multirow{2}{*}{$\begin{array}{c}\text { Repair } \\
\text { System }\end{array}$} & \multicolumn{7}{|c|}{ Alignment No. } & Repair Size \\
\cline { 2 - 8 } & 1 & 2 & 3 & 4 & 5 & 6 & 7 & 8 & Average \\
\hline A & $12 \%$ & $18 \%$ & $22 \%$ & $10 \%$ & $26 \%$ & $51 \%$ & $16 \%$ & $14 \%$ & $21 \%$ \\
\hline B & $12 \%$ & $21 \%$ & $15 \%$ & $10 \%$ & $22 \%$ & $29 \%$ & $16 \%$ & $12 \%$ & $17 \%$ \\
\hline C & $12 \%$ & $18 \%$ & $15 \%$ & $10 \%$ & $22 \%$ & $29 \%$ & $15 \%$ & $12 \%$ & $17 \%$ \\
\hline D & $12 \%$ & $18 \%$ & $22 \%$ & $10 \%$ & $28 \%$ & $22 \%$ & $16 \%$ & $10 \%$ & $17 \%$ \\
\hline
\end{tabular}




\section{A. Mapping Removing Result}

Table 10 describes the results of a diagnosis that focuses on the number of deleted mappings (Removed column) and the total CV from removed mapping (Total CV column). System A removes more mapping in alignment experiments no. 5 and 6. Especially in experiment no. 6 stated that the system that adopted the Greedy method removes far more mappings, i.e. 46 (column xi) and with a total CV much higher (column xii) when compared to the other three systems.

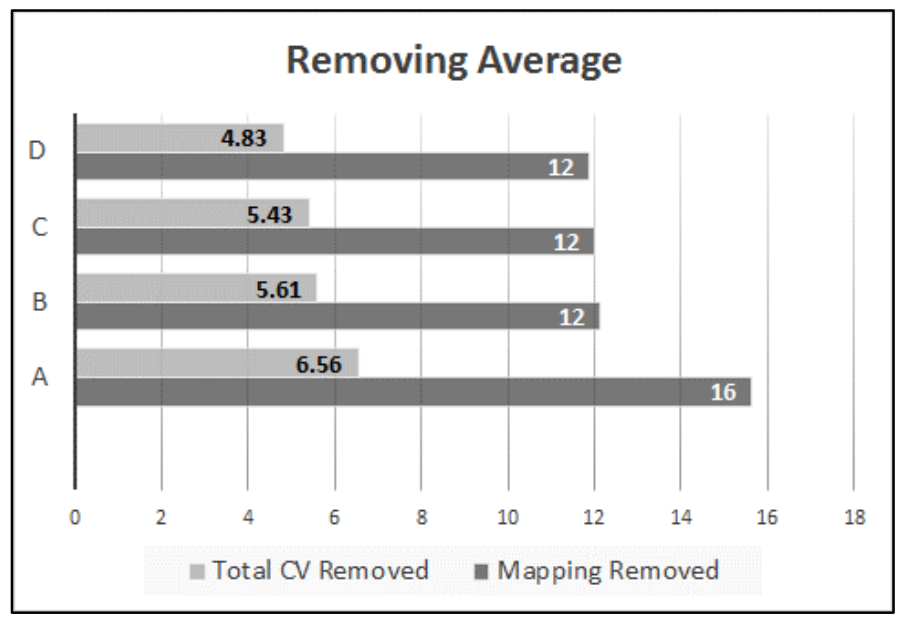

Figure 6. Removing Average Chart

Repair sizes average of $\mathrm{B}, \mathrm{C}$, and D systems are smaller than system $\mathrm{A}$ on the number of removed mapping (Table 11). The average removal of mappings and the total cv from removed mapping for each system can be seen in Figure 6 . The system D removes the mapping with the lowest total $\mathrm{CV}$, meaning that system $\mathrm{D}$ tends to delete the mapping with a low level of validity. System C and B delete mapping with total CV ranging from 5.43 to 5.61. System D is the best meets the minimal goal of diagnosis in minimizing the confidence value of removed mapping. The proposed system, namely system $\mathrm{B}$, is the third-best in reducing the confidence value of removed mapping. System A removes the mapping with the highest total CV compared to the other three systems, meaning that system $\mathrm{A}$ is the least meets the minimal goal of diagnosis in minimizing the confidence value of removed mapping. Based on the number of removed mapping, system D, C dan B is the best meets the minimal goal of diagnosis in minimizing the number of removed mapping. The three systems remove the mapping with the smallest number, which is an average of 12 mappings in 8 trials. Whereas the system $\mathrm{A}$ is the least meets the minimal goal of diagnosis in minimizing the number of removed mapping.

Table 12. Conflict Set Resolving Result

\begin{tabular}{|c|c|c|c|c|c|c|c|c|c|c|c|c|c|c|c|c|}
\hline Alignme & \multicolumn{2}{|c|}{1} & \multicolumn{2}{|c|}{2} & \multicolumn{2}{|c|}{3} & \multicolumn{2}{|c|}{4} & \multicolumn{2}{|c|}{5} & \multicolumn{2}{|c|}{6} & \multicolumn{2}{|c|}{7} & \multicolumn{2}{|c|}{8} \\
\hline $\begin{array}{l}\text { Repair } \\
\text { System }\end{array}$ & $\begin{array}{c}\text { CS } \\
\text { After } \\
\text { Repair } \\
\text { (i) }\end{array}$ & $\begin{array}{c}\text { CS } \\
\text { Resolv } \\
\text { ed } \\
\text { (ii) }\end{array}$ & $\begin{array}{c}\text { CS } \\
\text { After } \\
\text { Repair } \\
\text { (iii) }\end{array}$ & $\begin{array}{c}\text { CS } \\
\text { Resolv } \\
\text { ed } \\
\text { (iv) }\end{array}$ & $\begin{array}{c}\text { CS } \\
\text { After } \\
\text { Repair } \\
\text { (v) }\end{array}$ & $\begin{array}{c}\text { CS } \\
\text { Resolv } \\
\text { ed } \\
\text { (vi) }\end{array}$ & $\begin{array}{c}\text { CS } \\
\text { After } \\
\text { Repair } \\
\text { (vii) }\end{array}$ & $\begin{array}{c}\text { CS } \\
\text { Resolv } \\
\text { ed } \\
\text { (viii) }\end{array}$ & $\begin{array}{c}\text { CS } \\
\text { After } \\
\text { Repair } \\
\text { (ix) }\end{array}$ & $\begin{array}{c}\text { CS } \\
\text { Resolv } \\
\text { ed } \\
\text { (x) }\end{array}$ & $\begin{array}{c}\text { CS } \\
\text { After } \\
\text { Repair } \\
\text { (xi) }\end{array}$ & $\begin{array}{c}\text { CS } \\
\text { Resolv } \\
\text { ed } \\
\text { (xii) }\end{array}$ & $\begin{array}{c}\text { CS } \\
\text { After } \\
\text { Repair } \\
\text { (xiii) }\end{array}$ & $\begin{array}{c}\text { CS } \\
\text { Resolv } \\
\text { ed } \\
\text { (xiv) }\end{array}$ & $\begin{array}{c}\text { CS } \\
\text { After } \\
\text { Repair } \\
\text { (xv) }\end{array}$ & $\begin{array}{c}\text { CS } \\
\text { Resolv } \\
\text { ed } \\
\text { (xvi) }\end{array}$ \\
\hline $\mathrm{A}$ & 0 & $100 \%$ & 0 & $100 \%$ & 0 & $100 \%$ & 0 & $100 \%$ & 0 & $100 \%$ & 0 & $100 \%$ & 0 & $100 \%$ & 0 & $100 \%$ \\
\hline B & 0 & $100 \%$ & 0 & $100 \%$ & 0 & $100 \%$ & 0 & $100 \%$ & 0 & $100 \%$ & 0 & $100 \%$ & 0 & $100 \%$ & 0 & $100 \%$ \\
\hline $\mathrm{C}$ & 1 & $93 \%$ & 0 & $100 \%$ & 0 & $100 \%$ & 0 & $100 \%$ & 0 & $100 \%$ & 0 & $100 \%$ & 1 & $96 \%$ & 0 & $100 \%$ \\
\hline D & 0 & $100 \%$ & 0 & $100 \%$ & 0 & $100 \%$ & 0 & $100 \%$ & 0 & $100 \%$ & 58 & $58 \%$ & 0 & $100 \%$ & 5 & $74 \%$ \\
\hline
\end{tabular}




\section{B. Conflict Set Resolving Result}

The experiment of resolving CS in Table 12 shows that two systems resolve all CS, namely system A and B. Two other systems do not entirely resolve all CS in 8 trials, namely system C and D. System C leaves $1 \mathrm{CS}$ in experiment 1 (columns i) and 7 (column xiii), while system C leaves 59 CS (column xi) and 4 CS (column xv). Figure 7 shows the CS resolved chart of four systems compared.

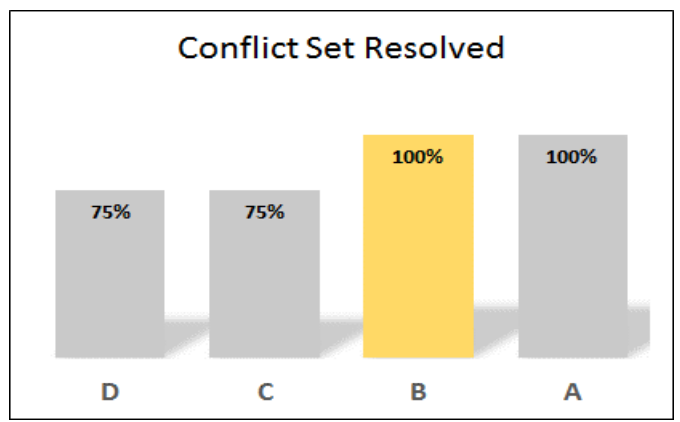

Figure 7. Conflict Set Resolved Chart

Two systems fulfill the goal of alignment incoherence repair which eliminates the conflicts mapping in alignment, namely B and A, including the proposed system. Heuristic function based on dynamic weighting implemented in the Greedy Search method can produce alignment output that is free of conflict mapping.

Figure 8 shows that both Greedy Proposed (B) and Greedy Current (A) produce 100\% free from conflict mapping, this indicates that both systems meet one of the objectives of the study. But then Figure 7 shows that Greedy Current (A) removes more mapping and produces enormous total confidence value of removed mapping than the other three systems. When combining Figures 8 and 7, the repair system that is following the research objectives is the Greedy Proposed system (B).

\section{Checking Unsatisfiable on Conflict-Free Mapping}

Section 1 explains that the main discussion of this study is to produce conflict-free mapping in output alignment, and the purpose of the repair process is to restore incoherent to coherent alignment. The definition of mapping incoherence is if an unsatisfiable concept or class is found in O1UO2UM (definition 2). The definition of alignment incoherence is if an incoherent mapping is found in alignment, on the contrary, if no incoherent mapping is found then the output alignment has been coherent (definition 3). Thus it is necessary to check the absence of unsatisfiable class in the output alignment to prove that the absence of conflict mapping the coherent of alignment. We checked unsatisfiable classes on output alignment with a reasoner system with the Pellet library ${ }^{1}$.

Table 13. Checking Unsatisfiable

\begin{tabular}{|c|c|c|c|c|c|}
\hline $\begin{array}{l}\text { Repair } \\
\text { System }\end{array}$ & $\begin{array}{l}\text { Alignment } \\
100 \% \text { CS } \\
\text { Resolved }\end{array}$ & $\begin{array}{l}\text { Conflict } \\
\text { Mapping } \\
\text { Exist? }\end{array}$ & $\begin{array}{c}\text { Unsatisfiable } \\
\text { Class } \\
\text { Exist? }\end{array}$ & $\begin{array}{c}\text { Mapping } \\
\text { Status } \\
\text { (Definition 2) }\end{array}$ & $\begin{array}{c}\text { Alignment } \\
\text { Status } \\
\text { (Definition 3) }\end{array}$ \\
\hline (i) & (ii) & (iii) & (iv) & (v) & (vi) \\
\hline A & 8 & \multirow{5}{*}{ No } & \multirow{5}{*}{ No } & \multirow{5}{*}{$\begin{array}{c}\text { No } \\
\text { Mapping } \\
\text { Incoherence }\end{array}$} & \multirow{5}{*}{$\begin{array}{l}\text { Alignment } \\
\text { Coherence }\end{array}$} \\
\hline B & 8 & & & & \\
\hline $\mathrm{C}$ & 6 & & & & \\
\hline D & 6 & & & & \\
\hline Total & 28 & & & & \\
\hline
\end{tabular}


There were 28 output alignments with $100 \%$ CS resolved based on the conflict set resolving results (Table 12). Conflict mapping checks were carried out manually (column iii), while unsatisfiable checks were carried out computerized. The checking result is not any unsatisfiable class found in the conflict-free mapping (column iv). We can conclude that the conflict-free mapping output alignment is alignment coherence, based on definition 3 (column vi).

\section{Conclusion}

Diagnosis is one of the subprocesses in alignment incoherence repair, to eliminate semantic conflict mapping in alignment by removing some mappings. Since mapping is an important knowledge resource for building links on Linked Data, it is necessary to eliminate conflict mapping with minimal impact on input alignment. This study implements a diagnosis with two minimization focus, which minimizes the number of removed mapping and minimizes the total confidence value of the removed mapping.

We propose a dynamic weighted based heuristic to the Greedy Best-first Search method to search for minimal unwanted mapping. The experiment results show that the proposed system reduces the number of removed mapping and the total $\mathrm{CV}$ of removed mapping at once, while producing conflict-free mapping. We also checked the existence of unsatisfiable in the output alignment, the result is no unsatisfiable class found so that the conflict-free alignment is said to be coherent.

The Greedy search method gives a faster solution than $\mathrm{A}^{*}$ because it calculates only one value, namely $h$ (node), at each level of expansion. Whereas the $\mathrm{A}^{*}$ method calculates two values of $g$ (node) and $h$ (node) at each level of expansion so that more effort is taken by the system. The experimental results show that the $\mathrm{A}^{*}$ method is not better in producing conflict-free mapping with the dynamic weighting technique and the median rule applied therein.

\section{References}

[1]. I. G. Husein, B. Sitohang, and S. Akbar, "Peningkatan Interlinking pada Linked Data Melalui Ontology Alignment," in Seminar Nasional Teknologi Informasi dan Multimedia 2016, 2016.

[2]. J. Euzenat and P. Shvaiko, Ontology Matching. Springer, 2013.

[3]. A. Algergawy, M. Cheatham, D. Faria, A. Ferrara, I. Fundulaki, I. Harrow, S. Hertling, E. Jiménez-Ruiz, N. Karam, A. Khiat, P. Lambrix, H. Li, S. Montanelli, H. Paulheim, C. Pesquita, T. Saveta, D. Schmidt, P. Shvaiko, A. Splendiani, E. Thiéblin, C. Trojahn, J. Vataščinová, O. Zamazal, and L. Zhou, "Results of the ontology alignment evaluation initiative 2008," in CEUR Workshop Proceedings, 2008, vol. 2288, p. 76-116.

[4]. E. Jiménez-Ruiz, C. Meilicke, B. C. Grau, and I. Horrocks, "Evaluating mapping repair systems with large biomedical ontologies," in CEUR Workshop Proceedings, 2013, vol. 1014, p. 1000-1010.

[5]. C. Meilicke and H. Stuckenschmidt, "Incoherence as a basis for measuring the quality of ontology mappings," in CEUR Workshop Proceedings, 2008, vol. 431, p. 1-12.

[6]. J. luis Aguirre, K. Eckert, J. Euzenat, A. Ferrara, C. Meilicke, A. Nikolov, J. Pane, F. Scharffe, P. Shvaiko, H. Stuckenschmidt, O. Zamazal, V. Svatek, and C. Trojahn, "Results of the Ontology Alignment Evaluation Initiative 2012," in Proc. 8th ISWC workshop on ontology matching (OM), 2013, p. 61-100.

[7]. P. Lambrix, G. Qi, and C. Meilicke, "ISWC tutorial 2011," 2011. Available: http://www.ida.liu.se/ patla00/courses/ISWC11/.

[8]. C. Pesquita, D. Faria, E. Santos, and F. M. Couto, "To repair or not to repair: Reconciling correctness and coherence in ontology reference alignments," in CEUR Workshop Proceedings, 2013, vol. 1111, p. 13-24.

[9]. J. Noessner, H. Stuckenschmidt, C. Meilicke, and M. Niepert, "Completeness and optimality in ontology alignment debugging," in CEUR Workshop Proceedings, 2014, vol. 1317, p. 25-36.

[10]. D. Faria, E. Jiménez-Ruiz, C. Pesquita, E. Santos, and F. M. Couto, “Towards annotating 
potential incoherences in BioPortal mappings," in The Semantic Web - ISWC 2014, 2014, p. $17-32$.

[11]. E. Jiménez-Ruiz and B. Cuenca Grau, "LogMap: Logic-based and scalable ontology matching," in Lecture Notes in Computer Science (including subseries Lecture Notes in Artificial Intelligence and Lecture Notes in Bioinformatics), 2011, vol. 7031 LNCS, no. PART 1, p. 273-288.

[12]. C. Meilicke, “Alignment Incoherence in Ontology Matching," Dissertation. 2011.

[13]. I. G. Husein, B. Sitohang, and S. Akbar, "Diagnosis Process with Two Focuses Minimal in Incoherent Mapping Repair," in International Electronics Symposium on Knowledge Creation and Intelligent Computing (IES-KCIC), 2017, p. 228-231.

[14]. S. Schlobach, Z. Huang, R. Cornet, and F. Van Harmelen, "Debugging incoherent terminologies," J. Autom. Reason., vol. 39, no. 3, p. 317-349, 2007.

[15]. C. Meilicke, "Home of ALCOMO," 2012. Available: http://web.informatik.unimannheim.de/alcomo/\#ref1.

[16]. I. G. Husein, B. Sitohang, S. Akbar, and F. N. Azizah, "Comparisons of Diagnosis in Mapping Repair Systems," in 2016 International Conference on Data and Software Engineering (ICoDSE), 2016.

[17]. I. G. Husein, B. Sitohang, S. Akbar, and F. N. Azizah, "Optimal Path Finding Algorithm Using Weighted Based Heuristic for Incoherent Mapping Repair," in International Conference on Data and Software Engineering, 2018.

[18]. B. C. Grau, Z. Dragisic, K. Eckert, R. Granada, V. Ivanova, E. Jim, P. Lambrix, B. C. Grau, Z. Dragisic, and K. Eckert, "Results of the Ontology Alignment Evaluation Initiative $2015, " 2015$.

[19]. W. E. Djeddi, M. T. Khaidir, and S. Ben Yahia, “XMap : Results for OAEI 2015," in CEUR Workshop Proceedings, 2015, p. 216-221.

[20]. I. G. Husein, B. Sitohang, and S. Akbar, "Minimizing the Estimated Solution Cost with A * Search to Support Minimal Mapping Repair," in 2017 4th International Conference on Electrical Engineering, Computer Science and Informatics (EECSI 2017), 2017, no. September, p. 19-21.

[21]. I. G. Husein, B. Sitohang, S. Akbar, and F. N. Azizah, "Global Minimal Diagnosis Algorithm For Repair Incoherent Mappings in Ontology Alignment," in 2018 19th IEEE/ACIS International Conference on Software Engineering, Artificial Intelligence, Networking and Parallel/Distributed Computing (SNPD), 2018, p. 317-321.

[22]. D. Fleischhacker and H. Stuckenschmidt, "A practical implementation of semantic precision and recall," in CISIS 2010 - The 4th International Conference on Complex, Intelligent and Software Intensive Systems, 2010, vol. 2, p. 986-991.

[23]. A. Solimando, E. Jiménez-Ruiz, and G. Guerrini, "On the Feasibility of Using OWL 2 DL Reasoners for Ontology Matching Problems," in Informal Proceedings of the 4th International Workshop on OWL Reasoner Evaluation (ORE-2015) co-located with the 28th International Workshop on Description Logics (DL 2015), Athens, Greece, June 6, 2015, 2015, p. 1-15.

[24]. E. Santos, D. Faria, C. Pesquita, and F. M. Couto, "Ontology alignment repair through modularization and confidence-based heuristics," J. PLOS ONE, vol. 10, no. 12, p. 1-19, 2015.

[25]. F. Baader, D. L. McGuinness, D. Nardi, and P. F. Patel-Schneider, THE DESCRIPTION LOGIC HANDBOOK: Theory, implementation, and applications. 2003.

[26]. C. Meilicke and H. Stuckenschmidt, "An Efficient Method for Computing Alignment Diagnoses," in International Conference on Web Reasoning and Rule System, 2009, p. 182 196.

[27]. T. Ivanova, “Ontology Alignment,” Int. J. Knowl. Syst. Sci., vol. 1, no. 4, p. 22-40, 2010.

[28]. F. Scharffe and J. Euzenat, "Linked data meets ontology matching : enhancing data linking through ontology alignments," 2013.

[29]. S. Russell and P. Norvig, Artificial Intelligence: A Modern Approach (Third Edition).

${ }^{1}$ https://github.com/stardog-union/pellet 
Prentice Hall, 2010.

[30]. M. T. Jones, Artificial Intelligence A System Approach. New Delhi: Infinity Science Press LLC, 2008.

[31]. B. Coppin, Artificial Intelligence Illuminated, 1st ed. Canada: Jones and Bartlett Publishers, 2004.

[32]. S. Juhana, M. H. Siti Farhana, and M. N. Shahrul Zaman, "Symbiosis of Thesaurus, Domain Expert and Reference Sources in Designing a Framework for the Construction of a Multilingual Ontology for Islamic Portal," Int. J. Electr. Eng. Informatics, vol. 4, no. 1, p. 120-133, 2012.

[33]. O. Zamazal, "OntoFarm Project,” 2016. . Available: https://owl.vse.cz/ontofarm/.

[34]. OAEI-2018, "Conference track OAEI-2018." Available: http://oaei.ontologymatching.org/2018/conference/.

[35]. I. G. Husein, B. Sitohang, S. Akbar, and F. N. Azizah, "Optimal Path Finding Algorithm Using Weighted Based Heuristic for Incoherent Mapping Repair," in International Conference on Data and Software Engineering, 2018, p. 100-105.

[36]. Q.-V. Tran, R. Ichise, and B.-Q. Ho, "Cluster-based Similarity Aggregation for Ontology Matching," in 6th International Workshop on Ontology Matching, 2011.

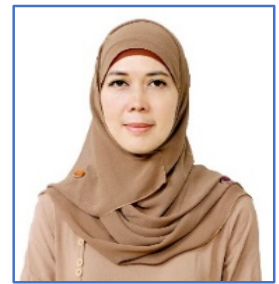

Inne Gartina Husein is a Doctoral Program Student in School of Electrical Engineering and Informatics (STEI) at Institut Teknologi Bandung since 2014. She has been a lecturer in Telkom University since 2007. Her research interests span in Database and Knowledge Engineering. She received a S.Kom. from STMIK LIKMI in 2000. She received a M.T. from Institut Teknologi Bandung in 2005.

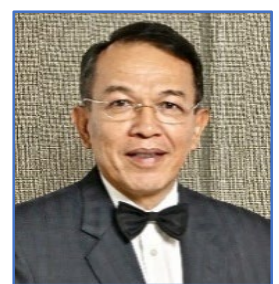

Benhard Sitohang is a Professor in School of Electrical Engineering and Informatics (STEI) at Institut Teknologi Bandung, where he has been since 1980 . He has been serving as the Chairman of Knowledge and Software Engineering Research Group in STEI since 2013. His research interests span in Database, Programming and Software Engineering. He received an Ir. from Institut Teknologi Bandung in 1978. He received a M.S. and a Dr.Ing. from Université des Sciences et Techniques de Languedoc, France in 1981 and 1983.

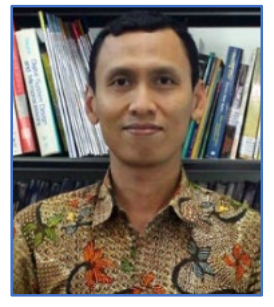

Saiful Akbar is a lecturer in School of Electrical Engineering and Informatics (STEI) at Institut Teknologi Bandung, where he has been since 1998. He has been serving as Informatics Study Program Chair since 2016. His research interests are both in 3D Model Similarity Retrieval and Software Engineering. He received a S.T in 1997 and a M.T. in 2002 from Institut Teknologi Bandung. He received a Dr.techn. from Johannes Kepler Universitat Linz, Austria in 2007.

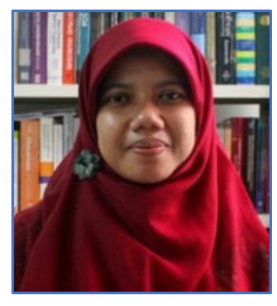

Fazat Nur Azizah is a lecturer in School of Electrical Engineering and Informatics (STEI) at Institut Teknologi Bandung, where she has been since 2009. Her research interests span in Data and Software Engineering. She received a S.T from Institut Teknologi Bandung in 2002, and a M.Sc. from HAN University, Netherlands in 2005. She received a Dr. from Institut Teknologi Bandung in 2011. 